DOI: http://dx.doi.org/10.12775/ths.2018.002

\author{
Ariadna Strugielska* \\ Nicolaus Copernicus University in Toruń \\ Ariadna.Strugielska@umk.pl \\ Katarzyna Piątkowska* \\ Nicolaus Copernicus University in Toruń \\ kapia@umk.pl
}

\title{
Challenges with defining competence for foreign language learning and teaching on the basis of the Common European Framework of Reference
}

\begin{abstract}
In this paper we take a critical look at the approach to competence in the Common European Framework of Reference (Council of Europe, 2001a) and highlight inconsistencies in defining, structuring and positioning the notion in the model for foreign language learning and teaching presented in the document, which translates into lack of consistency in the interpretation of competence in research
\end{abstract}

* Ariadna Strugielska is an assistant professor in the Department of English at Nicolaus Copernicus University in Torun. Her research interests include educational discourse, quality in higher education, intercultural communicative competence and teaching English as a foreign language. She has published extensively on intercultural aspects in applied linguistics research.

** Katarzyna Piątkowska is an assistant professor in the Department of English at Nicolaus Copernicus University in Torun. Her research interests include intercultural communicative competence and teaching English as a foreign language. She has published numerous papers on intercultural competence and presented the results of her research at many international conferences.

*** We would like to thank Paula Budzyńska for her preliminary research on the CEFR, which contributed to this paper. 
based on the Common European Framework of Reference (Council of Europe 2001a).

Keywords: competence; the Common European Framework of Reference; foreign language; learning and teaching.

\section{Introduction}

Set in an action-based approach and describing "in a comprehensive way what language learners have to learn to do in order to use a language for communication and what knowledge and skills they have to develop so as to be able to act effectively" (Council of Europe, 2001a, p. 1), the Common European Framework of Reference (hereafter the CEFR) (Council of Europe, 2001a) provides a taxonomic model of competences of the foreign language learner viewed as both an individual and a social agent. Striving to reflect the complexity of human language, the CEFR (Council of Europe, 2001a) breaks competence down into separate components, treating the notion as a composite structure. Dealing with the communicative situation and carrying out tasks and activities, the learner mobilizes "a number of competences developed in the course of their previous experience. In return, participation in communicative events (including, of course, those events specifically designed to promote language learning) results in the further development of the learner's competences, for both immediate and long-term use" (Council of Europe, 2001a, p. 101). The CEFR (Council of Europe, 2001a, p. 1) maintains that competence is manifested through the whole human being since "communication calls upon a whole human being. Interacting in complex ways, competence results in the development of human personality. The CEFR (Council of Europe, 2001a) in its introductory chapter provides two definitions of competence. Namely, the notion is defined as knowledge, skills and attitudes (Council of Europe, $2001 \mathrm{a}$, p. V) or as "the sum of knowledge, skills and characteristics that allow a person to perform action" (Council of Europe, 2001a, p. 9). In this paper we analyze competence for foreign language learning and teaching as presented in the CEFR (Council of Europe, 2001a) and demonstrate that it is defined and structured in an unbalanced and inconsistent way, going beyond the declared definition focusing on general competences and communicative language competences as a system of knowledge, skills, attitudes and characteristics as components of competence. Next, we highlight the complex relations between competences themselves, which impede the analysis 
of the notion under discussion. Finally, we demonstrate that incongruities in the nature of competence in the CEFR (Council of Europe, 2001a) affect the interpretation of the notion in studies (Bagarić \& Djigunović, 2007; Cambridge University Press, 2013; Matheidesz \& Heyworth, 2007; Hodel, 2007; North, 2014; North, Ortega \& Sheehan, 2011). Namely, research highlights different facets of competence to various degrees and differs in its perception of competence from the CEFR (Council of Europe, 2001a).

\section{Competence according to the CEFR (Council of Europe, 2001a)}

According to the CEFR (Council of Europe, 2001a) the learner develops a range of competences (general and communicative language competences) drawing on a number of competences at their disposal under various conditions and constraints, which leads to the modification and reinforcement of the learner's competences. Consequently, competence in the CEFR (Council of Europe, 2001a) is described in terms of a structured overview of the foreign language learner's competences divided into language-related competences referred to as communicative language competences (i.e. linguistic competences, sociolinguistic competence and pragmatic competences) and competences less closely related to language (i.e. general competences) (Council of Europe 2001a, p. 101). These two types of competences are declared to consist of knowledge and skills. Yet, broken down into several components in a taxonomic way, competence within the areas of general competences and communicative language competences is equated with knowledge, ability, skills, awareness, control, and use, which allow the learner to perform the action.

The components of general competences include knowledge (i.e. declarative knowledge of the world, of the society and culture of the community or communities in which a language is spoken, and intercultural awareness) and its equivalent in skills (including practical, intercultural skills and know-how) (Council of Europe 2001a, pp. 101-105). However, the aspects of interculturality in respect to declarative knowledge are referred to as awareness, which lets us conclude that not only awareness but also knowledge is equated with competence. The CEFR (Council of Europe, 2001a) admits that "the boundaries between knowledge of the world (CEFR 5.1.1.1), sociocultural knowledge (CEFR 5.1.1.2) and intercultural awareness (CEFR 5.1.1.3) are not really clear-cut, (...). Nor are those between practical skills and know-how (CEFR 5.1.2.1) - which includes social skills - and socio-cultural knowledge or intercultural skills and knowhow (5.1.2.2)" 
(Council of Europe, 2017, pp. 52-53). Therefore, it can be concluded that knowledge, awareness, skills and know-how, which make up competence, are representations of the same notion.

A wider scope of constructs is included in the area of existential competence, which is connected with attitudes, motivations, values, beliefs, cognitive styles and personality types of the learner (Council of Europe, 2001a, p. 105). Competence is also defined as ability with reference to ability to learn, which in turn is equated with awareness (of language, communication, general phonetics) and skills (i.e. study skills and heuristic skills) (Council of Europe, 2001a, p. 106-108). Moreover, competence is characterised, for instance, by the following aspects: four basic skills, more linguistic skills or types of interaction (Cambridge University Press, 2013). Competence has been defined similarly throughout the years - mainly in terms of knowledge and skills, sometimes also ability. However, neither of the documents of the Council of Europe (2001a, 2013) justifies such a division or extension of competence.

In the same vein, communicative language competences, i.e. linguistic, sociolinguistic and pragmatic competences consist of knowledge and skills (Council of Europe, 2001a, p. 158). However, the constructs of these three types of competence include not only knowledge and skills, but also ability, awareness, control and use.

According to the CEFR (Council of Europe, 2001a, p.13) "linguistic competences include lexical, phonological, syntactical knowledge and skills and other dimensions of language as system". Grammatical competence is viewed as the knowledge of and ability to understand and express meaning by producing and recognising well-formed phrases and sentences in accordance with these principles (as opposed to memorising and reproducing them as fixed formulae) (Council of Europe, 2001a, p. 112). Similarly, lexical competence is termed as the knowledge of and ability to use the vocabulary of language (Council of Europe, 2001a, p. 110). In the same vein, orthoepic competence is defined as an interplay of knowledge and ability (i.e. "knowledge of spelling conventions", "knowledge of the implications of written forms, particularly punctuation marks, for phrasing and intonation", "ability to consult a dictionary and a knowledge of the conventions used there for the representation of pronunciation", "ability to resolve ambiguity (homonyms, syntactic ambiguities, etc.) in the light of the context") (Council of Europe, 2001a, p. 118). Phonological and orthographic competences are associated with knowledge and skills in the perception and production of the elements of language (Council of Europe, 2001a, 116117). However, semantic competence deals with awareness and control 
of the organization of meaning (Council of Europe, 2001a, p. 115). Thus, competence in relation to linguistic competences is a system of knowledge, ability, skills, awareness and control.

Sociolinguistic competence is defined as the knowledge and skills required to deal with the social dimension of language use. (Council of Europe, 2001a, p. 118). However, much of what is discussed in respect to sociolinguistic competence refers to language use (e.g. the use of linguistic markers of social relations, politeness conventions, expressions of folk wisdom, register differences, dialect and accent), which may speak to the fact that competence in this case is seen as use.

Pragmatic competences are defined as knowledge (i.e. the knowledge of the ways messages are organized, used and sequenced) (Council of Europe, 2001a, p. 123). Yet, the ability of a user to arrange sentences in sequence so as to produce coherent stretches of language is taken into consideration in the definition of discourse competence (Council of Europe, 2001a p. 123). Similarly, functional competence is defined as use with reference to spoken discourse and written texts. The same model is kept in the 2017 version of the CEFR (Council of Europe, 2017). However, this version of the Framework introduces design competence as part of pragmatic competence.

Plurilingual and pluricultural competence, which is not located in the schematic model of the learner's competence, is referred to as the ability to both use languages for the purposes of communication and take part in intercultural interaction, where a person, viewed as a social agent has proficiency, of varying degrees, in several languages and experience of several cultures (Council of Europe, 2001a, p. 168). In respect to plurilingual competence, the CEFR (Council of Europe, 2001a) understands competence as resulting from the sum of various types of monolingual competence the learner represents. On the other hand, competence in integrated pluricultural competence is viewed as consisting of various types of competence, i.e. cultural being a sum of different cultures, i.e. national, regional etc., plurilingual culture and multiple competence being part of partial competence (belonging to the sphere of general competences), which interact to produce integrated pluricultural competence (Council of Europe, 2001a, pp. 6, 135). However, the extended version of the CEFR (Council of Europe, 2017, p. 165) introduces a new scale, exploiting pluricultural repertoire (through general competences, pragmatic competence and sociolinguistic competence), which refers to the use of pluricultural competences in a communicative situation, thus interpreting competence as a skill rather than knowledge or attitudes.

With regard to communicative competence the notion of competence in the CEFR (Council of Europe, 2001a, p. 4) is defined as experience 
and knowledge, which refers to experience of the language of the home, experience of the language of society, experience of the languages of other people and knowledge of language.

Furthermore, competence in the CEFR (Council of Europe, 2001a) is also equated with acquaintance in relation to receptive competence, which is mentioned in the document only once in the following manner: "acquaintance with more formal or more familiar registers is likely to come over a period of time, perhaps through the reading of different text-types, particularly novels, at first as a receptive competence" (2001a, p. 120). This notion is used also in the 2017 version of the Framework in one of the descriptors for the B2 level: "can follow a conversation happening around him/her in a language or languages in which he/she has receptive competence, and express his/her contribution in a language that is understood by one or more of the interlocutors" (2017, p. 227). However, neither of the documents explains the notion or includes it in the schematic representation of the learner's competences. Similarly, multiple competence is mentioned in the CEFR (Council of Europe, 2001a, pp. 135, 168) twice. Although it can be inferred that plurilingual and pluricultural competence is called multiple competence, the notion is not further explained in the document.

Thus, competence for language learning and teaching is, on the one hand, an internally complex category comprising both static and dynamic, inborn and context-dependent elements and, on the other hand, a superordinate category whose subordinates are general and communicative language competences. Competence within these two subordinates consists of many component categories such as knowledge, ability, skills, awareness, control, and use, which are configured in various ways, depending on the way competence is modified (i.e. if it is e.g. existential or intercultural competence).

\section{The positioning of competences in the model}

The CEFR (Council of Europe, 2001a) considers some types of competence as related or unrelated to one another. To begin with, the Framework (Council of Europe, 2001a, p. 158) points to the relationship between general competences and language-related competence by stressing that "tasks of any kind require the activation of a range of appropriate general competences, for example: knowledge and experience of the world; sociocultural knowledge (concerning life in the target community and essential differences between practices, values and beliefs in that 
community and the learner's own society); skills such as intercultural skills (mediating between the two cultures), learning skills, and everyday practical skills and know-how (see section 5.1)". The role of the interplay between general competences and communicative language competences is further strengthened by the statement that "all human competences contribute in one way or another to the language user's ability to communicate and may be regarded as aspects of communicative competence" (Council of Europe, 2001a, p. 101). Consequently, although not specific to language, general competences are mobilized for actions of all kinds, including language activities. Thus, general competences support communicative language competences, which allow the learner to act using linguistic means (Council of Europe, 2001a, p. 9).

However, there are aspects of general competences and the relations within these competences which are unclear. Namely, only two components of general competences, i.e. strategic and learning competences, are described as transversal (Hodel, 2007, p. 7). Further inconsistency relates to the learners' savoir-être referred to as either existential competence or psycho-social competence while sociocultural competence is considered as intercultural competence when the comparison of the world of origin and the world of the target community is involved (Hodel, 2007, p. 8). Yet, as Hodel (2007, p. 8) emphasizes, sociocultural competence equated with intercultural competence, although mentioned in the CEFR (Council of Europe, 2001a), is not located anywhere in the model presented in the Framework (Council of Europe, 2001a).

The CEFR (Council of Europe, 2001a) distinguishes between communicative competence and communicative language competences, with the distinction between these two types of competence not being clearly delineated. While in chapter 5 of the CEFR (Council of Europe, 2001a) communicative language competences are referred to in terms of three types of components, i.e. linguistic, sociolinguistic and pragmatic competences, communicative competence is defined as language-related and called upon along with general capacities by the learner for the realization of communicative intentions. Also communicative competence is placed outside the schematic representation of the learner's competences. However, the same chapter of the CEFR (Council of Europe, 2001a, p. 108) discusses communicative competence as consisting of linguistic, sociolinguistic and pragmatic competences.

Furthermore, the CEFR (Council of Europe, 2001a, p. 136) equates communicative language competence with plurilingual and pluricultural competences viewed as whole and includes varieties of a native language and 
varieties of one or more foreign languages as components of communicative language competence. Yet, rather than viewing plurilingual and pluricultural competences as "the superposition or juxtaposition of distinct competences", the CEFR (Council of Europe, 2001a, p. 168) sees it as "the existence of a complex or even composite competence on which the user may draw". Consequently, with reference to plurilingual and pluricultural competence, the CEFR (Council of Europe, 2001a, p. 168) considers competence as a multiple notion with pluricultural dimensions where "links between the development of abilities concerned with relating to other cultures and the development of linguistic communicative competence " are not emphasized.

The nature of plurilingual and pluricultural competence is unclear in the CEFR (Council of Europe, 2001a). Firstly, the CEFR (Council of Europe, 2001a) mentions plurilingual and pluricultural competence (Council of Europe, 2001a, pp.133, 134, 135, 136, 137, 138, 168, 174, 175, 176) and plurilingual and pluricultural competences (Council of Europe, 2001a, pp. 133, 171, 175) without specifying similarities and/or differences or relationship between them. Secondly, the Framework stresses that the learner's proficiency can be greater in one language than in the others. Thirdly, the profile of competence in various languages may differ. For example, a learner may attain excellent speaking competence in two languages but good writing competence in only one language (Council of Europe, 2001a, p. 133). Furthermore, plurilingual and pluricultural competence is subject to change (the document calls it an uneven competence) and its profile depends on the learner's career, family history, travel experience, reading and hobbies, causing changes in the learner's plurilingualism and leading to an imbalanced profile of competence (Council of Europe, 2001a, p. 133). Consequently, the CEFR (Council of Europe, 2001a) admits that the profile of competence in relation to plurilingual and pluricultural competence is partial. Being part of multiple competence, partial competence is both a functional competence and a part of plurilingual and pluricultural competence, whose imperfect nature at a given moment it profiles. The CEFR (Council of Europe, 2001a, p. 135) refers the notion of partial competence to different components of the learner's proficiency. Moreover, plurilingual and pluricultural competence enhances communication awareness and metacognitive strategies as well as uses and further develops pre-existing sociolinguistic and pragmatic competences and leads to hyperlinguistic awareness. (Council of Europe, 2001a, p. 134)

To sum up, relationships between competences are unclear in the CEFR (Council of Europe, 2001a), i.e. they can act as both subordinate and superordinate categories. Moreover, competences reveal a different degree 
of dynamicity in the process of development (plurilingual competences appear to be the most fluctuating out of all competences). Finally, some competences are indispensable for other competences, e.g. sociolinguistic competences are prerequisites for plurilingual competences.

\section{The notion of competence in studies}

The incongruities in the nature and positioning of competences in the CEFR (Council of Europe, 2001a) is reflected in studies focusing on competence for language learning and teaching based on the Framework (2001a) which oscillate between different components of competence in defining the construct.

Namely, the notion is conceived as the knowledge, skills and attitudes that enable the learner to use language effectively (Matheidesz \& Heyworth, 2007, p. 7). Bagarić and Djigunović (2007, p. 99) point to the inconsistency in defining competence in the CEFR (Council of Europe, 2001a), noticing that communicative competence is interpreted only as knowledge with each component of language knowledge "defined as knowledge of its contents and ability to apply it". Based on the CEFR (Council of Europe, 2001a), Hodel (2007, p. 7) interprets competence as a set of areas of knowledge, or aptitudes and skills and of attitudes and existential competences (savoir-être) with the proportion of knowledge, skills and savoir être varying from one competence to another. Consequently, socio-cultural competence is interpreted by Hodel (2007, p. 8) as consisting of knowledge, skills and existential competences relating to the distinctive characteristics of a particular society. Linguistic competence in the CEFR (Council of Europe, 2001a), as Hodel (2007, p. 8) notices, comprises the knowledge and skills of features of language systems such as lexis, phonology and syntax which are considered independent of both the socio-linguistic aspects of use and pragmatic functions of the utterances produced. Socio-linguistic competence in the CEFR (Council of Europe, 2001a) is seen by Hodel $(2007$, p. 9) as referring to the knowledge and skills involved in using language in a social context. A competence of acquisition, i.e. ability to learn, is defined as the ability to observe new language experiences, to participate in them and to integrate the new knowledge, which may entail modifying previous knowledge (Hodel, 2007, p. 9). As a result, in an attempt to clarify the concept of competence, Hodel (2007, p. 9) calls for redefining a competence of acquisition (ability to learn) in the CEFR (Council of Europe, 2001a), which will integrate all types of competence. Being transversal in nature, a competence of acquisition 
pertains to all competences (including itself) and all activities. Dealing with a difficult task, a learner has to mobilize different competences to carry the task out, which requires the use of various strategies. Having appropriate strategies and knowing how to use them is called by Hodel $(2007$, p. 9) an additional transversal competence, which language teachers relate to linguistic competence (e.g. how to learn vocabulary and grammar or what kind of strategies to use when coming across new words).

The notion of competence is also seen as reflecting various kinds of cognitive processes, strategies and knowledge or comprising various aspects, from strategic, through pragmatic to linguistic (North, Ortega \& Sheehan, 2011, pp. 8-13).

Another interpretation of competence refers to sub-skills, i.e. the basic four skills (speaking, reading, writing and listening), communicative language (e.g. turn-taking, asking for clarification), types of interaction (e.g. obtaining goods and services, interviewing) and linguistic skills (e.g. vocabulary range, phonological control) (Cambridge University Press, 2013, p. 6).

North $(2014$, p. 22) stresses that competence understood as language proficiency and reflected in the accomplishment of the task is determined by "the interaction between the strategies employed and the relevant aspects of competences that can be mobilised in the particular context concerned, given the conditions and constraints operating at the time".

North, Ortega and Sheehan (2011), Bagarić and Djigunović (2007), Hodel (2007), Matheidesz and Heyworth (2007) introduce the term strategic competence, which is not present in the CEFR (Council of Europe, 2001a). North, Ortega and Sheehan (2011, p. 16) incorporate it under pragmatic (functional and discourse competence) and linguistic competence (grammatical, lexical and phonological/orthographic). Furthermore, based on the CEFR (Council of Europe, 2001) the authors distinguish five competences that learners need, namely, pragmatic, linguistic, sociolinguistic, strategic and intercultural, which differs from the division of competences in the Framework.

Based on the quality dimension of the Framework (Council of Europe, 2001a), Matheidesz and Heyworth (2007) present their structured overview of the learner's competences, which differs from the model of the CEFR (Council of Europe, 2001a). Firstly, general competences are not included in the scheme. The reason why general competences are not mentioned is that the document focuses on descriptors, which have not been distinguished for general competences. Rather than referring to communicative language competences, they introduce the concept of communicative language competence, thus making language-related competence as a manifestation 
of one type of competence, which is divided into linguistic, sociolinguistic and pragmatic competence. Therefore, as opposed to relating to 6 scales in the quality dimension of communicative language competencies (Council of Europe, 2001b), which cover only linguistic aspects, the Matheidesz and Heyworth (2007) extend the model to 13 scales, referring to linguistic, sociolinguistic and pragmatic dimensions of competence. Namely, within the area of linguistic competence, reference is made to vocabulary range and general range (rather than general linguistic range present in the Framework (Council of Europe, 2001a)) and grammatical accuracy, vocabulary, phonological and orthographic control. Additionally, Matheidesz and Heyworth (2007, p. 22) discuss sociolinguistic aspects and pragmatic dimensions (i.e. flexibility, taking the floor, thematic development, coherence, propositional precision and spoken fluency).

North, Ortega and Sheehan (2011) take into consideration only those competences which are applicable to particular situations, i.e. those which are applied to practice. The authors justify such a course of action on the grounds that "the CEFR-based scenario concept offers a means to: work top down from real world contexts to identify the competences needed to be successful in them, plus criteria to judge that success. Both the communicative language activities listed and the aspects of competence needed to be successful in them suggest classroom activities" (2011a, p. 17).

Confusion arises concerning the status of learning competence in literature. Hodel (2007, p.10) notices that "learning skills (savoirapprendre) (see CEFR 5.1.4, p. 106-107), CEFR 2.1.1, p. 11) bring into play existential competence, knowledge and skills, and depend on a combination of competences (i.e. they call on transversal application of competences). The element of savoir-être in learning competence involves being "open to discover otherness" whether it be another language, another culture, other people or fresh knowledge". Thus, the above excerpt suggests that learning skills can be interpreted as learning competence.

Matheidesz and Heyworth (2007, p. 5) point to the relationship between competences and activities and notice that competences are exploited and modified by the learner in the process of communication. Having at their disposal a limited number of competences, the learner can carry out a large number of activities, which are further affected by the learner's personal factors such as attitudes, motivation, values, beliefs, cognitive styles and personal traits. Matheidesz and Frank Heyworth (2007, p. 7) call these aspects existential competences and link them to the learner's personality as components of the learner's emotional, affective, cognitive and social attitudes. Consequently, a number of competences are mobilized by the 
learner to perform a task, which leads to a communicative use of language (Matheidesz and Frank Heyworth, 2007, p. 4).

Another problem concerning the interpretation of competence lies in the fact that some names of assumably the same competences differ across studies. For example, existential competence is called by Hodel (2007) psycho-social competence while ability to learn is termed transversal competence, which leads to confusion.

In almost all the analysed studies, relations between the competences indicated in the CEFR (Council of Europe, 2001a) are not included - the authors do not provide such relations between competences graphically in their studies (except for Hodel (2007) and Using the CEFR (2011).

\section{Conclusions}

The structure and the positioning of the competences in the CEFR (Council of Europe, 2001a) is not clear. Contrary to the declaration that competence within general competences and communicative language competences is defined as knowledge and skills, it is in fact equated with notions such as knowledge, ability, skills, awareness, control or use. Even more problematic is the nature of communicative language competence(s) and plurilingual and pluricultural competence(s) as it is not obvious if these competences are plural or simply their constructs are instantiations of a single competence. The above analysis shows that studies based on the CEFR (Council of Europe, 2001a) confuse these competences. Perhaps the reason for such a blurred definition of competence(s) lies in the following statement: "as is the case with different aspects of communicative language competences, or of plurilingual and pluricultural competences, distinctions are made to assist reflection, but real communication requires a holistic integration of different aspects." (Council of Europe, 2017, p. 114)

Furthermore, there is a problem with locating communicative competence and plurilingual and pluricultural competence(s) on the scheme as the connection is not entirely clear.

Appearing only once or twice in the documentation and their meaning not further developed, some competences, e.g. multiple competence, receptive competence arguably need clarification.

Certain competences are introduced in the documents following the original CEFR (Council of Europe, 2001a), for example, strategic competence or transversal competence. Descriptors for some competences were completed later. For instance for plurilingual and pluricultural 
competence(s) they were added in 2017 , which proves that the document and its key terms have been evolving.

As demonstrated above, a schematic (or taxonomic) representation fails in the case of defining a construct such as competence in the CEFR (Council of Europe, 2001a). Interrelated between themselves and outside themselves (e.g. the relation between competences and activities or characteristics), competences in the CEFR (Council of Europe, 2001a) are extremely challenging to classify or structure. The use of various terminology with reference to the same category does not facilitate the analysis of competence in the document. Therefore, we may tentatively conclude that the nature of competences is too complex and the connections between them too numerous for competence to be categorized.

\section{References}

Bagarić, V. \& Mihaljević Djigunović, J. (2007). "Defining Communicative Competence." Metodika, 8, 94-103.

Cambridge University Press. (2013). Introductory Guide to the Common European Framework of Reference (CEFR) for English Language Teachers. Cambridge: Cambridge University Press.

Council of Europe. (2001a). Common European Framework of Reference for Languages: Learning, teaching, assessment. Strasbourg: Council of Europe.

Council of Europe. (2001b). Common European Framework of Reference for

Languages: Learning, teaching, assessment. Structured overview of all CEFR scales. Strasbourg: Council of Europe.

Council of Europe. (2017). Common European Framework of Reference for Languages: learning, teaching, assessment. Companion Volume with New Descriptors. Strasbourg: Council of Europe.

Hodel, H. P. (2007). "The Common European Framework: Activities, competences, levels (2004-2007), ECML's 2nd medium-term programme 2004-2007. Training teachers to use the European Language Portfolio." Retrieved from http://archive.ecml.at/mtp2/elp_tt/results/DM_layout/00_10/03/03\%20 CEF\%20text\%20E.pdf.

Matheidesz, M. \& Heyworth, F. (2007). The Eaquals Self-Help Guide for Curriculum and Syllabus Design. Retrieved from https://www.eaquals.org/wp-content/ uploads/Eaquals-Self-Help-Guide-for-Curriculum-and-Syllabus-Design.pdf.

North, B. (2014). The CEFR in Practice. Cambridge: Cambridge University Press.

North, B., Ortega, A. \& Sheehan, S. (2011). Core Inventory for General English. British Council.

University of Cambridge ESOL. (2011). Using the CEFR: Principles of Good Practice. Cambridge: Cambridge University Press. 